\title{
Comments on dyadic Green's functions and induced currents
}

\author{
Appel-Hansen, Jørgen
}

Published in:

Proceedings of the 8th Mediterranean Electrotechnical Conference

Link to article, DOI:

10.1109/MELCON.1996.551216

Publication date:

1996

Document Version

Publisher's PDF, also known as Version of record

Link back to DTU Orbit

Citation (APA):

Appel-Hansen, J. (1996). Comments on dyadic Green's functions and induced currents. In Proceedings of the 8th Mediterranean Electrotechnical Conference (Vol. Volume 3, pp. 1427-1428). IEEE.

https://doi.org/10.1109/MELCON.1996.551216

\section{General rights}

Copyright and moral rights for the publications made accessible in the public portal are retained by the authors and/or other copyright owners and it is a condition of accessing publications that users recognise and abide by the legal requirements associated with these rights.

- Users may download and print one copy of any publication from the public portal for the purpose of private study or research.

- You may not further distribute the material or use it for any profit-making activity or commercial gain

- You may freely distribute the URL identifying the publication in the public portal

If you believe that this document breaches copyright please contact us providing details, and we will remove access to the work immediately and investigate your claim. 


\title{
Comments on Dyadic Green's Functions and Induced Currents
}

\author{
Jørgen Appel-Hansen \\ Department of Electromagnetic Systems \\ Technical University of Denmark \\ Building 348, DK-2800 Lyngby, Denmark \\ Phone (45) 45-881444 Fax (45) 4.5-931634 E-Mail: FD@emi.dtu.dk
}

\begin{abstract}
The note formulates the wave equation in regions with induced currents in the case of scattering by a perfect conductor. By using this formulation the ordinary solution using the dyadic Green's function for the problem is discussed. The region of validity of this solution is pointed out. A claimed need for conventions is alleviated by referring to Gauss's law.
\end{abstract}

\section{SCATTERING BY A PERFECT CONDUCTOR}

Let a current distribution $\bar{J}(\bar{r})$ in a volume $V$ be placed in an open region outside a perfect electrical conductor with surface $S$ as shown in Fig. 1. Suppressing the time factor $e^{j \omega t}$, the wave equation is written in the form

$$
\nabla \times \nabla \times \overline{\mathrm{E}}(\overline{\mathrm{r}})-\mathrm{k}_{0}^{2} \overline{\mathrm{E}}(\overline{\mathrm{r}})=-j \omega \mu_{0} \overline{\mathrm{J}}(\overline{\mathrm{r}})
$$

and solved for the boundary condition

$$
\hat{\mathrm{n}} \times \overline{\mathrm{E}}=0 \text { on } \mathrm{S}
$$

where $\overline{\mathrm{E}}$ is the electric field intensity at a field point characterized by the position vector $\overline{\mathbf{r}}$. Free space conditions are characterized by the wave number $\dot{\mathrm{k}}_{0}=\omega \sqrt{\mu_{0} \varepsilon_{0}}$ where $\omega$ is the angular frequency, $\mu_{0}$ is the magnetic permeability, and $\varepsilon_{0}$ is the electric permittivity. The unit vector $\hat{\mathrm{n}}$ is pointing from $\mathrm{S}$ out of the conductor. The solution of the problem is

$$
\overline{\mathrm{E}}=-j \omega \mu_{0} \int_{\mathrm{V}} \overline{\overline{\mathrm{G}}}_{1}\left(\overline{\mathrm{r}}, \overline{\mathbf{r}}^{\dagger}\right) \cdot \overline{\mathrm{J}}\left(\overline{\mathbf{r}}^{\prime}\right) \mathrm{d} \mathrm{V}^{\prime}
$$

where $\overline{\bar{G}}_{1}$ is the dyadic Circen's function for the problem which satisfies the equation

$$
\nabla \times \nabla \times \overline{\bar{G}}_{1}\left(\bar{r}, \overline{\mathrm{r}}^{\prime}\right)-\mathrm{k}_{0}^{2} \overline{\mathrm{G}}_{1}\left(\overline{\mathrm{r}}, \mathrm{r}^{\prime}\right)=-\overline{\overline{\mathrm{I}}} \delta\left(\overline{\mathrm{r}}-\overline{\mathrm{r}}^{\prime}\right)
$$

proper radiation conditions at infinity, and the boundary condition

$$
\hat{\mathrm{n}} \times \overline{\overline{\mathrm{G}}}_{1}\left(\overline{\mathrm{r}}, \overline{\mathrm{r}}^{\prime}\right)=0 \text { on } \mathrm{S}
$$

After the solution of the problem, the magnetic field intensity $\overline{\mathrm{H}}$ may be found from Maxwell's equations. Furthermore, the so-called induced surface current $\bar{J}_{\text {es }}$ may be found from

$$
\overline{\mathrm{J}}_{\mathrm{es}}=\hat{\mathrm{n}} \times \overline{\mathrm{H}}
$$

0-7803-31-09-5/96/\$5.00@ 1996 IEEE where $\overline{\mathrm{H}}$ is the magnetic field intensity on the outer surface of $S$. This is the ordinary formulation, e.g., [Tai, pp. 62 - 66]. Although the formulation uses a boundary condition on $S$ for the $\overline{\mathrm{E}}$-field this field is not found in the region of induced currents on $\mathrm{S}$. It is understood that the values to use for $\overline{\mathrm{E}}$ and $\overline{\overline{\mathrm{G}}}_{1}$ in Eqs. (2 and 5) are those on the outer side of $S$. By this terminology is meant that values are obtained from a limiting process in which the outer side of $S$ is approached without reaching a point exactly on $S$. It should be mentioned that [Morse and Feslibach, p. 805] leaves it to a matter of convention to indicate the field exactly on $S$. The purpose of the present note is to point out that in the present case this is not necessary due to Gauss's law. Thus, it depends on the situation whether a convention should be used. To clarify the meaning of being exactly on $S$, the wave equation is stated in the complete space, i.e., not only in the open region outside the conductor as in the case of Eq. (1).

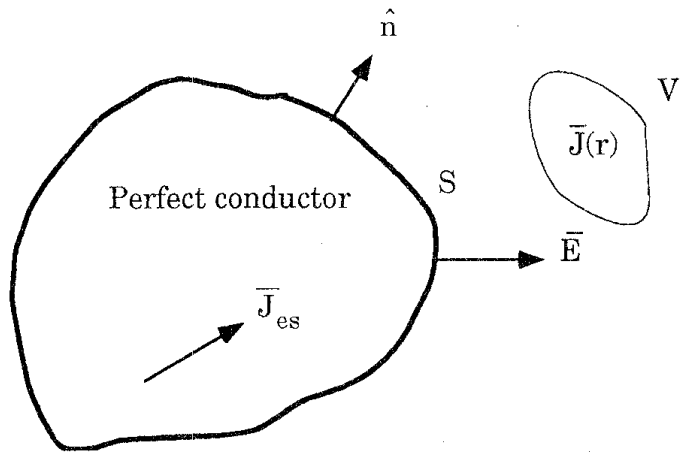

Fig. 1. Perfect conductor illuminated by a current distribution.

Let us first write $\overline{\mathrm{E}}$ as the sum of the impressed field $\overline{\mathrm{E}}^{\mathrm{i}}$ (defined as the field from $\overline{\mathrm{J}}(\overline{\mathrm{r}})$ in tree space without the conductor) given by

$$
\overline{\mathrm{E}}^{\mathrm{i}}=-j \omega \mu_{0} \int_{\mathrm{V}} \overline{\mathrm{G}}_{0}\left(\overline{\mathrm{r}}, \overline{\mathrm{r}}^{\prime}\right) \cdot \overline{\mathrm{J}}\left(\overline{\mathrm{r}}^{\prime}\right) \mathrm{d} V^{\prime}
$$

and the scattered field $\overrightarrow{\mathrm{E}}^{\mathrm{S}}$ (defined as the field from the induced current $\overline{\mathrm{J}}_{\mathrm{es}}=\hat{\mathrm{n}} \times \overline{\mathrm{H}}$ suspended in free space without the conductor) given by

$$
\overline{\mathrm{E}}^{s}=-j(\omega) \mu_{0} \int_{\mathrm{S}} \int_{\mathrm{S}} \overline{\overline{\mathrm{G}}}_{0}\left(\overline{\mathbf{r}}, \overline{\mathbf{r}}^{\prime}\right) \cdot[\hat{\mathrm{n}} \times \overline{\mathrm{H}}] \mathrm{d} \mathrm{S}^{\prime}
$$

where $\overline{\bar{G}}_{0}(\overline{\mathrm{r}}, \overline{\mathrm{r}})$ is the free space dyadic Green's function which satisfies the same equations and conditions as $\overline{\overline{\mathrm{G}}}{ }_{1}$, except Eq.(5). 
Thus

$$
\overline{\mathrm{E}}=\overline{\mathrm{E}}^{\mathrm{i}}+\overline{\mathrm{E}}^{\mathrm{s}}
$$

Inside the conductor, $\overline{\mathrm{E}}^{\mathrm{i}}$ and $\overline{\mathrm{E}}^{\mathrm{s}}$ cancel each other in order to give zero field in these regions.

Noting that the currents in space are $\bar{J}(\overline{\mathbf{r}})$ and $\bar{J}_{\mathrm{es}}, \overline{\mathrm{E}}$ satisfies the wave equation

$$
\nabla \times \nabla \times \overline{\mathrm{E}}(\overline{\mathrm{r}})-\mathrm{k}_{0}^{2} \overline{\mathrm{E}}(\overline{\mathrm{r}})=-j \omega \mu_{0} \overline{\mathrm{J}}(\overline{\mathrm{r}})-\mathrm{j} \omega \mu_{0} \delta(\mathrm{n}) \overline{\mathrm{J}}_{\mathrm{es}}(\overline{\mathrm{r}})
$$

where $\delta(n)$ is a delta function associated with a direction nomal to the surface $S$. The function $\delta(n)$ is zero for $\overline{\mathrm{r}}$ not on $\mathrm{S}$. The induced current $\bar{J}_{\mathrm{es}}$ should be determined so that the solution of Eq. (10) satisfies the same conditions as the solution in the form of Eq. (3). Although we do not lind the induced current, Eq. (10) is the wave equation in a form which includes the induced current region. Now, insertion of Eq. (3) into Eq. (10) shows clearly that Eq. (3) is a solution of Eq. (10) only outside the region of induced currents. 'This is due to the fact that Eq. (1), solved for the boundary condition Eq.(2), excludes the region of induced currents and the perfect conductor. However, it should be noted that in case Eq. (3) is used inside the perfect conductor a zero field is obtained.

From the discussion given above it is apparent that we have to be careful in specifying the region in which we solve a problem. This is related to the meaning of being on the boundary $S$. Depending on the context, the meaning is: (a) On the outer surface of $S$ where $\bar{E}$ is different from zero, (b) in the region of induced currents, or (c) on the inner surface of $S$ where $\bar{E}$ is zero. As it appears from a previous paragraph, the field on the outer or inner side of $S$ is found from a limiting process in which the relevant side of $S$ is approached without reaching a point exactly on $S$. The limiting process is often described by using such terminology as, e.g., the value of the field just outside S. However, such terminology has led to misinterpretations, e.g., in the case of equivalence principles using equivalent charges or . currents "just in front of S." As outlined in [Morse and Feshbach, p.797], "it might be expected that the equivalence breaks down" between the current and $S$. In fact, the equivalence really breaks down since there is a gap between the current and $S$ and this gap is not present in the original problem [Appel-Hansen, 1987]. The problem discussed is also related to the "fallacy" of presenting the boundary conditions [Tai, 1972].

As seen the field exactly on $S$, i.e., in the region of induced currents is not found so far using the Green function terminology above. However, using Gauss's law, it can be proved that the field exactly on $S$ in the case of a surface charge density on $S$ is

$$
\overline{\mathrm{E}}=\frac{\overline{\mathrm{E}}^{+}+\overline{\mathrm{E}}^{-}}{2}
$$

where $\overline{\mathrm{E}}^{+}$and $\overline{\mathrm{E}}^{-}$are the field intensities on the outer and inner sides of S, respectively [Ferraro, 1954].

\section{REFERENCES}

[1] C-T Tai, "Dyadic Green functions in electromagnetic theory," The Institute of Electrical and Electronics Engineers, Inc., New York, 1993.

[2] P. M. Morse and H. Feshbach, "Methods of theoretical physics," Part I, McGraw-Hill Book Company, Inc., New York, 1953.

[3] J. Appel-Hansen, "Comments on field equivalence principles," IEEE Trans. Antennas and Propagation, Vol. AP-35, No. 2, pp. 242-244, Feb. 1987

[4] C-T Tai, "On the presentation of Maxwell's theory," Proceedings of the IEEE, vol. 60, no. 8, pp. 936 945, August 1972

[5] V. C. A. Ferraro, "Electromagnetic theory, "The Athlone Press, University of London, p. 74, 1954 